\title{
The Unprotected Port: A Legal Appraisal of Data- Driven (Programmatic) Advertising In Nigeria
}

\author{
Samuel Omodolapo Bakare, Ogundele Tolulope \\ The Department of Computer Science and Media Technology, Malmö University, Sweden
}

\begin{abstract}
Since the advent of web 2.0, the increasing importance of data has become centre of debate amongst various stakeholders. One of the resultant effects of open access internet is the improvement of advertising and marketing technologies and methods. Programmatic advertising (PA) is one of the byproducts of the new internet age. This form of advertising uses consumers' personal data and behaviour online for the creation of customized ads for brands through third-party data aggregators. Personal data are auction to the highest bidders in real-time and instantaneously to expose customized messages and ads to the audience. Based on its population and increasing level of internet penetration, Nigeria is a fallow, free-for-all, and datamining ground for many tech companies. Hence, the adoption of programmatic advertising is nascent and insidiously creeping into the advertising space in Nigeria. This paper focused on the implication of programmatic advertising from the perspective of existing legal specifications currently in Nigeria. Having given the conceptual premise of programmatic advertising (PA), the paper identified the ethical and legal implications of PA. based on the existing legal situation of personal data protection in Nigeria, the paper recommends, amongst others, that to avoid the potential violations of user's right to data privacy, the onus is on various stakeholders- the data controllers, tech companies, and lawmakers- to ensure that their activities provide stronger protection of personal data.
\end{abstract}

Keywords: Programmatic Advertising (PA), Personal Data, Regulations

\section{INTRODUCTION}

$\checkmark$ rom inception, the concept of marketing and advertising involves the deliberate process of exposing particular information to a pre-determined set of audiences based on the relationship of such audience on the information at hand (Kumar, 2012). The aim is to create a perception in the minds of the audience to create behavioral change (Solomon et al, 2006; Hassan et al, 2015; Pal \& Pal, 2019). As one of the prime indicators for successful marketing campaigns, advertising has weathered many evolutions; different types and forms have emerged over the last centuries. Durmaz (2011) and Kotler (2000) have identified various ways by organisations, which are armed with information, are targeting audience. each of these is aimed at isolating, reinforcing, and focusing messages in the minds of the unsuspecting public.

More than ever before, advertising has become so important as industrialization, automation, and a more efficient production process are on the increase in the $20^{\text {th }}$ century (Pal \& Pal, 2019). companies, organisations are aggressively vying to catch the presence and attention of the audience. As technologies improve, many companies are fine-tuning the means, methods, and processes of targeting the right set of public and audience for their products and services. Miller (2011) noted that the advent of online advertising opened a new wave of opportunities for companies. Online advertising has grown from zero in the 90s, Banner era, to a worth of over $\$ 333$ billion in 2019, AI era, and with a projection to grow more towards $\$ 517$ billion in 2023 (eMarketer, 2019).

Although Africa has low contributions in this estimate due to slow internet penetration in the African region in the 90s. As of 1994, sub-Sahara Africa only has $0.018 \%$ internet penetration. In 2015, the internet penetration was over $20 \%$ (World Bank, 2017). In this, Nigeria takes the lead with $8 \%$. However, at the end of 2020, Nigeria reached a top coverage of 154 million internet users making it the top 10 biggest internet users in the world (National Bureau of Statistics, 2020; Statista, 2021). Based on this, many companies have adopted digital-based technology to exploit the avalanche of digital footprints of Nigerians online for customized advertising. Since 2011, the internet ads generated revenue has moved from $\$ 10$ million to $\$ 73$ million, and with a projection of $\$ 133$ million in 2023.

Based on these indices, digital advertising has been having a filled-day on the data of Nigerians online for customized advertising. Nigerians' data have been commodified by technological giants - Facebook, Twitter, Instagram, and Google- and traded amongst the third party for financial gains.

This paper explores the conceptual premise of digital advertising, specifically focusing on programmatic advertising; definitions, opportunities, and dangers to the Nigerian online communities in the face of developing digital data laws and regulations in Nigeria. The paper also contributes to the raising work of literature and research on programmatic advertising in the Nigerian context. It is divided into sections; introduction, literature review; data laws and regulations in Nigeria, and recommendations relating to programmatic advertising and legal implications

\section{LITERATURE REVIEW}

\section{Programmatic advertising}

The liberalization of digital technology products in the area of marketing and advertisings is creating difficulty in having the precision of definition of programmatic advertising. The market is saturated with different products and companies using novel methods in differentiating themselves. Hence, this 
makes it more tasking to give a definite position to the concept of programmatic advertising (DoubleClick, 2014). Due to its effectiveness and growing demands, more marketers, companies, organisations are investing in such type of advertising. This form of advertising is has grossed almost $\$ 15$ billion worldwide in revenue as of 2015 (Lambrecht and Tucker, 2013; Aguirre et al., 2015; Benady, 2015; eMarketer, 2015). Almost half of all digital adverts were programmatically designed in 2015 and this is projected to increase by $80 \%$ in nearest future (Benady, 2015)

Conceptually, programmatic advertising has been identified with different characteristics by different people. Advertising Age Survey (2014), noted some terms that a group of sampled marketers identified with programmatic advertising. Out of 307 marketers, $40.1 \%$ mentioned audience targeting; $36.5 \%$ said real-time bidding, and 30\% noted automation. Truly all these characterized the concept of programmatic ads. Match2One (2020) defines it to be the application of AI and machine learning to buy advertising in real-time. This counters the traditional process of human negotiation and predetermined set prices. This is a similar position to Doubleclick (2014) which defined it as the practice of using technology (AI \& machine learning) and audience insights to automatically run an advert campaign in real-time to reach the right customer with the message in the right context. Programmatic advertising makes use of big data sets to distribute and disseminate personalised ads materials to a well-defined target audience while incorporating real-time pricing and bidding (Benady, 2015; Funk \& Nabout, 2016). This was also similar to IAB Europe's definition (2014), which notes that programmatic trading simplifies the buying and selling process (of advertising) by bringing operational and pricing efficiency by digitally connecting the buyer and seller, therefore, enabling the programmatic purchase of advertising through trading platforms. In this, many inherent interplays of data interactions, transfers, data-bargaining, and automation occur. In this paper, Programmatic advertising is defined as the use of audience and customers data, via realtime bidding and pricing system, to bring and provide automated, customized advertising through the use of AI and machine learning technology.

There are many actors and units involved in the process of programmatic advertising. programmatic advertising premise on the basic idea of ad exchange via units of Demand Side Platforms (DSPs), Data aggregators or Data Management Platforms (DMPs), and Supply-Side platforms (SSPs). These actors are interlinked. Data Management Platforms document and profile customers' online information and activities: browsing behavior, purchase history, and personal site preferences via cookies stored on their personal computers. Data like location, region, weather, etc. can also be used. Based on this data, advertisers trigger demand-side platforms (DSPs) to trade those data for exposure to their brand by realtime bidding process amongst other brands that seek such data (Gertz \& McGlashan, 2016; Match2One, 2020). Supply-Side Platforms (SSPs) are those that are in charge of ad space inventory and published the adverts of successful brandsthose that come out with higher bidding during the auction. This interaction amongst these units takes place within $100 \mathrm{~ms}$ whenever a customer is online (Benady, 2015; Bush, 2016; Kosorin, 2016; Schafer and Weiss, 2016).

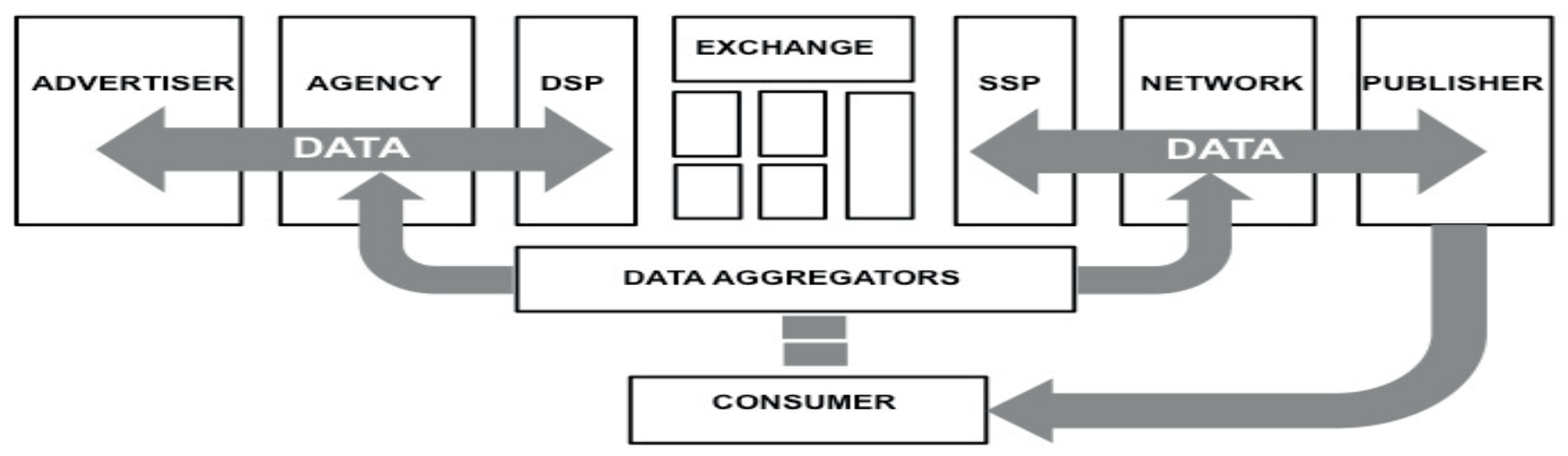

Figure 1: The programmatic advertising ecosystem (based on IAB, 2016)

Figure 1 gave the operational model of programmatic advertising. it visually identified players and the process of interactions amongst these players. Advertisers are those that have messages and materials to be heard, seen, or known of. Agency is the intermediary between advertisers (companies, brand owners, and organizations) Demand Side Platforms (DSPs). The agency takes the advertiser campaigns and materials and instructs DSPs (e.g Google ads, Facebook ads).
Demand Side Platforms are platforms that take the ads and bid, at the best price possible, for space on Ad exchange platforms. Ads exchange is an auction centre between DSPs and SSPs; a marketplace where products are selected based on real-time bidding to the SSPs. in an ad exchange platform, there are ad networks. SSPs are the last point before the audience receives the ad material or the message. they keep inventory of available (ads) space (Martínez-Martínez, 
Aguado \& Boeykens, 2017). Data Aggregators are one of the most important actors in this process. without the aggregators (Data Management Platforms), none of the other units can function. DMPs' function is to document and codify the online data and information of the audience and consumers. in realtime, these data are analysed for the best chance possible in all of the units.

For instance, an unsuspecting consumer search a query on google about wine and saw many links on the search. The consumer decided to enter one of the links. then changed her mind and leaves the computer. Immediately she comes online, different adverts about wine will start to come, even on a website unrelated to wine.

\section{What was going on:}

While the consumer was online the first time, the data aggregators are documenting every input from the consumer (name, email, profile, clicks, pages, etc.). Subsequently, due to ads material from a wine organisation that has launched a campaign via an agency on Demand Side Platforms. the next time, consumer come online with the same computer, a trigger alert occurs at the ad exchange centre for ads to be placed on her "face" since she was looking at the wine the last time, ad materials on wine be part of the auction to get space on the latest site the consumers is on.

Based on these, one of the criticisms of this form of digital advertising is the automated nature of allocation of adverts to a particular space based on available data; some outcomes do not accurately measure the current need of consumers on one hand. on the other hand, sometimes, exposure (on some sites) might not represent the (high) brand image of some organisations (Shehu, Nabout \& Clement, 2020). The development of defense mechanism against programmatic advertising; the use of web bots gave false impressions to ads materials, and adblockers impinging further penetration, impression, and effectiveness of this form of advertising (Fulgoni, 2016).

Importantly, the imperative survival of programmatic advertising lies with the availability of consumer data. Lee (2017) opined that data is critical to the relevance of AI and machine learning processes. The programmatic ecosystem rests on the process of data aggregation, and therefore it has important implications regarding operation and ethical premises (Watt, 2016).

\section{Ethical implications of programmatic advertising in Nigeria}

The advent of digital advertising created a new form of worry for advertisers, the government of nations, corporate organisations, and new forms of partnerships and relationships. Traditionally, ethics premises are often within the limits of trustworthiness, the scale of effects, cultural significance, and institutional controls (Drumwright \& Murphy, 2009). However, there are more concerns of data protection, corporate organisation exploitations, unrestricted forms of platforms' partnerships, and technical expertise for institutional control. the unhinged automation of data collection, management, and processes in advertising has created a new wave of ethical challenges and problems related to those that come up in market research ethics and as well as in the ethical debates in the implication big data (Nunan \& DiDomenico, 2013).

Programmatic advertising is exclusively part of the references by Acquisti (2009) and Feijoo-Gonzalez \& Gomez-Barroso (2013) which was called personal information economy. In the same light, Zuboff (2019) called this surveillance capitalism. This is where personal information is gathered, processed, managed, and effectively utilized as a core economic asset. In the process of programmatic advertising:

"data management platforms (DMPs) help produce a
single, coherent set of metrics that can be used to
intelligently describe, target, and track a consumer
audience across all channels and devices. DMPs
work hand-in-glove with demand-side platforms
(DSPs) to precisely deliver advertisements to the
right consumer, at the right time, and in the right
context" (Watts, pp 8, 2016).

This suggests an intensive utilization of personal data. Consequently, this calls for concerns of privacy and security (Tucker, 2012). the nature of the Programmatic advertising market, the level of efficiency, the position of consumers in the process scaled into higher concerns about the nature and the holders of such personal data Watt, 2016, Raine \& Duggan, 2016). Unlike the data usage of personal profiles by the likes of Netflix, Amazon, and eHealth, which are also data-driven services that depend on first or second-level data parties, for the Programmatic advertising ecosystem, it is third-party data players. In this, many of such parties are often unreliable in the protection of personal data with security holes and a lack of accountability for privacy issues (Ponemon Institute, 2016). The audience is often unaware of the activities of these third-party players on the use of the data. Martínez-Martínez \& Aguado (2014) noted that such premise isolates the process and procedure of seeking permission, like the case of first and second data party players, from audience or individuals that their data has been used during the process of programmatic advertising

Since the 2000s when digital media forms of advertising came, other regions of the world (the US and Europe) have created [and updated] laws and code of conduct behavour in the process of protecting the data of individuals online. General Data Protection Regulation, GDPR, gave, largely, protection for individuals' data that are collected by organisations within Europe. In the US also, the California Privacy Act is one of many regulations that protect the American public from data mining technology corporate organisations. There are also the combined laws between the EU and the US called the EU-US privacy shield. This triggers actionable guidelines for US companies that collect and 
process European citizens' data (Gibler, Crussell, Erickson, \& Chen, 2012).

Other regions, like Sub-Saharan Africa, are more reactionary to the fast-changing nature of data collection and process from tech companies. Nigeria represents the biggest source of personal data in the Sub-Saharan region. As one of the populous nations in the world with over 206 million people, Nigeria is one of the highly targeted markets for digital marketing; having 159 million people connected online; $41.4 \%$ of this population are connected through their mobile phones. it is projected that by 2025 , the number will increase to $64.9 \%$ (Stastista, 2020, World Bank, 2020). Based on this, digital advertising ( $\$ 99$ million) is one the most popular form of advertising in Nigeria- programmatic advertising is one of these- after TV, \$177 million, and Outdoor advertising \$133million (Statista, 2020). This form of advertising is bound to improve meteorically as internet penetration increases.

The first attempt of Nigeria's efforts to protect and regulate the data collection process was from the National Information Technology Development Agency (NITDA) which was established by an Act in 2007. In 2019, adopted the EU GDPR clauses and modified some areas to suit the peculiarities of the Nigerian economic space (Chika \& Tochukwu, 2020). major stakeholders within data protection governance in Nigeria are still within the preliminary stage of actions. According to Nigeria Communication Commission (2019), the promise to put in place an Internet Industry Code of Practice (IICP), which will spell out minimum acceptable behaviours relating to the provision and use of the internet in Nigeria, is still been put in place.

\section{Data and Digital laws and regulations in Nigeria Relevant} Legal Instruments

Nigeria, similar to most African countries does not have comprehensive data protection laws. The relevant regional laws on data protection are the African Union Convention on Cybersecurity and Personal Data Protection 2014 (Convention) and the Economic Community of West African States Supplementary Act on Personal Data Protection 2010 (The ECOWAS Data Protection Act).

The Data Protection Bill 2017, a bill that seeks to provide statutory protection and regulation for personal data, rights of data subjects, and the processing of personal data in Nigeria (Data Protection Bill, 2017) is being reviewed by the House of Assembly. Other legal frameworks that provide elements of data protection in Nigeria are; The Cybercrime Act 2015, The Freedom of Information Act 2011, The National Identity Management Commission Act 2007, The Nigerian Commissions Act, The Child's Rights Act, Credit Reporting 2017, The National Health Act 2014, and The Wireless Telegraphy Act 1998.

In the wake of the rising global concerns over data privacy and security breaches, the National Information Technology Development Agency (NITDA) in 2019 issued the Nigerian
Data Protection Regulation which serves as the main legal framework for the protection and regulation of personal data in Nigeria.

Data is at the heart of advertising. The personal data of users is the information exchanged between numerous entities to provide targeted advertisements to individuals. The processing of personal data is an activity that is undertaken by both private and public entities. Data Broker companies gather information about individuals from their online activities and transactions to sell to other companies for advertisement purposes (Google Help, 2021). The practice of real-time bidding which is focal to advertising essentially violates the principles of data privacy laws. In real-time bidding, information is collected each time a user visits a website, this information is offered to data brokers who send the information to advertisers (Google Help, 2021). Advertisers conduct bids to serve adverts to website visitors. The highest bidder wins and their advert is displayed to the user whose information was collected all in a matter of milliseconds (Baker, 2019).

The auction process involves the processing of large inventories of personal data by numerous entities in real-time (Jun Wang, 2017). These bids are processed through the use of automation every second (Infrastructure Options for RTB Bidders, 2021). The entire auction process involves the use of what constitutes the personal data of individuals under the NDPR and at the background of the NDPR lies the concept of consent. The information used by the entities during the auction process is usually those in which consent has been given for their use through a statement or a strong affirmative action (Lee, 2020). We will examine the definition of some keywords that will be used in the rest of this paper and explore the concept of consent in relation to programmatic advertising in subsequent paragraphs.

\section{Definitions}

'Personal Data' means any information relating to an identified or identifiable natural person ('Data Subject) ${ }^{1}$.

'Data Subject' is defined as any person, who can be identified, directly or indirectly, by reference to an identification number or one or more factors specific to their physical, psychological, mental, economic, cultural, or social identity ${ }^{2}$.

The Nigerian Data Protection Regulation (NDPR) defines "Processing" in almost exact words as the General Data Protection Regulation (GDPR), the European Regulation, the foremost regulation on data protection in the world, as
any operation or set of operations which is performed on Personal Data or sets of Personal Data, whether or not by automated means, such as collection, recording, organisation, structuring, storage, adaptation or alteration, retrieval,

\footnotetext{
${ }^{1}$ Section 1.3(xix) NDPR 2019

${ }^{2}$ Section 1.3(xiv) NDPR 2019
} 
consultation, use, disclosure by transmission, dissemination or otherwise making available, alignment or combination, restriction, erasure or destruction.

Similarly, the African Union Convention on Cybersecurity and Personal Data defines "processing of personal data" as:

Any operation or set of operations which is performed upon personal data whether or not by automatic means such as the collection, recording, organization, storage, adaptation, alteration, retrieval, backup, copy, consultation, use, disclosure by transmission, dissemination, or otherwise, making available, alignment or combination and locking, encryption, erasure or destruction of personal data.

The ECOWAS Supplementary Act on Personal Data Protection has a similar definition for "personal data processing", which is:

Any operation or set of operation carried out or not, with the assistance of processes that may or may not be automated and applied to data, such as obtaining, using, recording, organization, preservation, adaptation, alteration, retrieval, saving, copying, consultation, utilization disclosure by transmission, dissemination or otherwise, making available, alignment or combination as well as blocking, encryption, erasure or destruction of personal data.

\section{GUIDELINES ON CONSENT UNDER THE NDPR}

The NDPR being the foremost data protection regulation in Nigeria at the time of writing this paper came into force in 2019. Its objectives are as follows;

- To safeguard the rights of natural persons to data privacy;

- To foster safe-conduct for transactions involving the exchange of Personal Data;

- To prevent manipulation of Personal Data; and

- To ensure that Nigerian businesses remain competitive in international trade through the safe-guards afforded by a just and equitable legal regulatory framework on data protection and which is in tune with best practice.

Section 1.3(iii) of the NDPR defines 'consent' to mean

any freely given, specific, informed and unambiguous indication of the Data Subject's wishes by which he or she through a statement or a clear affirmative action, signifies agreement to the processing of Personal Data relating to him or her.

Section 2.2 further provides the guidelines for the lawful processing of personal data. The data subject must have given consent to the data controller for the processing of their personal data for one or more specific purposes. The author will discuss the valid elements of the notion of consent as it relates to real-time bidding and programmatic advertising as a whole.

\section{Elements of valid consent}

i. It must be freely given

The NDPR in Section 2.3 provides that the consent of the Data Subject must have been obtained without fraud, coercion, or undue influence. The data subject must make a deliberate choice to share their personal information for processing for the specific purpose it has been collected, where the consent choice is not deliberately made, such consent is regarded as null and void. Importantly, the data subject has the right to withdraw their consent at any time, and they must be informed of this right and the method to withdraw prior give consent ${ }^{3}$. When data processing is done to achieve several purposes, specific consent must be obtained for each purpose. For instance, where a webpage requests consent to send marketing emails and to share the user's data with a third party, consent must be requested specifically for each of these purposes. Where there are no two separate consents obtained for the two different purposes, the consent received will be deemed invalid. Therefore, data subjects must be free to select which purpose they accept that their personal data be used for (Lee, 2020). Furthermore, the data controller must be able to prove that the data subject consented to the processing of his or her personal data and that they have the legal capacity ${ }^{4}$ to do so.

\section{ii. It must be purpose-specific}

The consent given must be specific to the purpose for which it was given. For the processing of the personal data of an individual to be lawful, consent must have been given for one or more specific purposes ${ }^{5}$. This is reiterated in Section 2.3(1) which states that data must not be obtained except the specific purpose of the collection has been made known to the data subject. The requirement of specificity gives the user control over their data, therefore where the data collected is intended to be used for another purpose different from the one for which it was collected, fresh consent has to be obtained.

\section{iii. It must be informed}

Before giving consent, the data subject must be adequately informed about what they are consenting to and their rights. The request for consent must be communicated in a manner that is distinguishable from other matters, using plain words ${ }^{6}$. This means that information required to make a clear decision must not be hidden or disguised by words that may not be easy to understand or may have unclear meanings. An example of a right that they must be informed of is their right to withdraw consent. The NDPR also provides that any medium through which the personal data of people are

\footnotetext{
Section 2.3(2)(c) NDPR, 2019

${ }^{4}$ The NDPR does not define 'legal capacity'. Legal capacity refers to the ability of the data subject to validly give ther consent. Generally, under Nigerian laws, illiterates, infants, lunatics and drunkards do not have the capacity to enter contracts as they cannot validly give consent.

${ }^{5}$ Section 2.2(a) NDPR, 2019

${ }^{6}$ Section 2.3(2)(b) NDPR, 2019
} 
collected must display a privacy policy through which the user must be informed about the following;

- What constitutes the data subject's consent;

- Description of collectible personal information

- Purpose of collection of personal data

- Technical methods used to collect and store personal information, cookies, JWT, web tokens, etc.;

- Access (if any) of third parties to Personal Data and purpose of access;

- A highlight of the principles stated in Part 2 (of the regulation);

- Available remedies in the event of the violation; and

- The time frame for remedy.

iv. Consent must be an unambiguous indication of the data subject's wishes

The consent of the data subject must portray their wish to be bound by the agreement relating to the processing of their personal data. The unambiguous indication of the data subject's wish to have their personal data processed must be shown by a statement or clear affirmative action ${ }^{7}$. This shows the essential requirement for an intentional choice being made by a data subject to that particular processing that must have been stated.

It is important to note that consent must be obtained before the processing of any personal data may begin ${ }^{8}$. Therefore, where the purpose of the personal data collected changes, the data controller needs to obtain fresh consent before processing activity may continue. The processes involved in programmatic advertising are such in which personal data is transferred between several entities. The data controller may not be able to ascertain whether the use of the data is consistent with the purpose for which consent was obtained or where the data ends up. This is a massive breach of the provisions of the NDPR as regards consent (Baker, 2019).

Given the limitations of the NDPR to adequately protect the personal data of data subjects, there arose an urgent need to enact comprehensive laws, hence, the birth of the data protection bill. In the forthcoming paragraphs, we will examine the provisions of the proposed data protection bill concerning the sales of data amongst data controllers and third parties.

Programmatic advertising, as mentioned earlier, heavily relies on using the data of individuals to provide targeted advertisements to users. Real-Time Bidding which involves the auction of user's data to 'bidders' ensures that data passes through the hands of third parties who are not the data controller and who the data controller may not know about. This data is therefore sold to the highest "bidder". While the proposed Data Protection Bill ('Bill') has similar provisions with the NDPR concerning obtaining consent, the bill further stipulates the basic principles that must be complied with when processing personal data. Personal data must be processed for a specific, explicit, and legitimate purpose, and in a lawful, fair, and transparent manner, and processed for purposes compatible with that which it was initially collected. ${ }^{9}$ It further stipulates that obtaining or disclosing to a third party the personal data of an individual without their consent is an offense. The sales or advertisement of personal data, when obtained without consent, is also an offense according to the Bill ${ }^{10}$. Conversely, the Ghanaian Data Protection Act outrightly prohibits the purchase and sales of personal data of individuals whether or not consent is given ${ }^{11}$. This provision will serve to limit the transfer or sales of personal data for the use of advertisement, in turn giving individuals more control over their data and protecting their rights to privacy.

\section{RECOMMENDATIONS}

The right to data privacy is a fundamental right that is guaranteed by numerous international laws, constitutions, and regulations around the world. The nature of programmatic advertising is one where the processing of data and its final use, are isolated from the process of obtaining consent from the data subject(Martínez-Martínez \& Aguado 2014). The effect of this is that the privacy of users is grossly violated and their data may be used for activities they have not consented to. To avoid the potential violations of user's right to data privacy, the onus is on various stakeholders- the data controllers (DMPs), tech companies, and lawmakers- to ensure that their activities provide stronger protection of personal data.

Data Controllers, webpage publishers, and other data processors need to thoroughly understand the provisions of Section 2 of the NDPR. Only then, will they be able to frame their work in a way that people's privacy will not be breached.

Equally, lawmakers need to understand the complexities of emerging technologies. As the name implies, new technologies emerge daily therefore, lawmakers need to understand these technologies and be on top of issues as much as possible. There is a need for care to be taken when enacting legislation as it may end up stifling innovations. Again, already enacted laws and regulations should be revised periodically to keep up with the frequent changes in the technology ecosystem.

Technologically giants and data controllers must also embark on legal research to understand the peculiarities and specifications of legal frameworks that exist in Nigeria before the unfiltered utilisation of data from Nigeria. Facebook, Google, Amazon, Apple, and other large data miners should do an intensive market survey and engage stakeholders within Nigeria to create specific and customized legal restrictions or

\footnotetext{
${ }^{10}$ Section 44, Proposed Data Protection Bill

${ }^{11}$ Section 88, 89 Data Protection Act, 2012
}

${ }^{7}$ Section 1.3(iii) NDPR

${ }^{8}$ Section 2.3(i) NDPR 
peculiarities such as those in work in Europe and the US; this must also be replicated in Nigeria.

\section{REFERENCES}

[1] Acquisti, A. (2009). Nudging privacy: The Behavioral Economics of Personal Information. IEEE Security \& Privacy Magazine, 7(6), 82-85. https://doi.org/10.1109/msp.2009.163

[2] African Union Convention on Cybersecurity and Personal Data, 2014, Article 1, https://au.int/en/treaties/african-union-convention-cyber-securityand-personal-data-

protection

[3] African Union. (2014). African Union Convention on Cyber Security and Personal Data Protection. African Union Convention on Cyber Security and Personal Data Protection (Article 1) |. https://au.int/en/treaties/african-union-convention-cyber-securityand-personal-data-protection

[4] Aguirre, E., Mahr, D., Grewal, D., de Ruyter, K., \& Wetzels, M. (2015). Unraveling the Personalization Paradox: The effect of information collection and trust-building strategies on online advertisement effectiveness. Journal of Retailing, 91(1), 34-49. https://doi.org/10.1016/j.jretai.2014.09.005

[5] Benady, D. (2015) programmatic: Packed with Potential and Peril, Catalyst, Charted Institute of Marketing

[6] Busch, O. (2015). The Programmatic Advertising Principle. Management for Professionals, 3-15. https://doi.org/10.1007/9783-319-25023-6_1

[7] Chika, D. M., \& Tochukwu, E. S. (2020). An Analysis of Data Protection and Compliance in Nigeria. https://www.rsisinternational.org/journals/ijriss/Digital-

Library/volume-4-issue-5/377-382.pdf.

[8] Data Protection Act, 2012, S89, https://nita.gov.gh/wpcontent/uploads/2017/12/Data-Protection-Act-2012-Act-843.pdf

[9] Drumwright, M. E., \& Murphy, P. E. (2009). The Current State of Advertising Ethics: Industry and Academic Perspectives. Journal of Advertising, 38(1), 83-108. https://doi.org/10.2753/joa00913367380106

[10] Durmaz, Y. (2011, November 1). (PDF) A Theoretical Approach to the Concept of Advertising in Marketing . ResearchGate. https://www.researchgate.net/publication/229987556_A_THEOR ETICAL_APPROACH_TO_THE_CONCEPT_OF_ADVERTISI NG_IN_MARKETING.

[11] ECOWAS. (2010). Supplementary ACT A1SA.1F01F10 on Personal Data Protection (Article 1) https://www.statewatch.org/media/documents/news/2013/mar/eco was-dp-act.pdf.

[12] eMarketer. (2015). For Premium CPM Prices, the only way is up. eMarketer. https://www.emarketer.com/Article/Premium-CPMPrices-Only-Way-Up/1010960.

[13] Enberg, J. (2019). Global Digital Ad Spending 2019. Insider Intelligence. https://www.emarketer.com/content/global-digitalad-spending-2019.

[14] Fulgoni, G. M. (2016). Fraud in Digital Advertising: A Multibillion-Dollar black Hole: How marketers can minimize losses caused by bogus web traffic. Journal of Advertising Research, 56(2), 122. https://doi.org/10.2501/jar-2016-024

[15] Funk, B. \&, Nabout N.A. (2016) Cross-Channel Real-Time Response Analysis. In Bush, O (Eds),Programmatic Advertising The Successful Transformation to Automated, Data-Driven Marketing in Real-Time, Springer International Publishing.

[16] Gertz, O., \& McGlashan, D. (2015). Consumer-Centric Programmatic Advertising. Management for Professionals, 55-73. https://doi.org/10.1007/978-3-319-25023-6_5

[17] Gibler, C., Crussell, J., Erickson, J., \& Chen, H. (2012) AndroidLeaks: Automatically Detecting Potential Privacy Leaks in Android Applications on a Large Scale. Trust and Trustworthy Computing, 291-307. https://doi.org/10.1007/978-3-642-30921$2 \_17$

[18] Gómez-Barroso, J.-L., \& Feijóo-González, C. (2013). Información Personal: La NUEVA Moneda de la Economía digital. El
Profesional De La Informacion, 22(4), 290-297. https://doi.org/10.3145/epi.2013.jul.03

[19] Google. (2021). Infrastructure options for RTB bidders (part 4). Google.

https://cloud.google.com/architecture/infrastructure-options-forrtb-bidders

[20] Google's DoubleClick. (2014). The Programmatic Revolution: How technology is Transforming marketing. Google. https://www.thinkwithgoogle.com/marketing-

strategies/programmatic/the-programmatic-revolution/.

[21] Hassan, S., Nadzim, S. Z., \& Shiratuddin, N. (2015). Strategic Use of Social Media for Small Business Based on the AIDA MODEL. Procedia - Social and Behavioral Sciences, 172, 262-269. https://doi.org/10.1016/j.sbspro.2015.01.363

[22] HB02, Data Protection Bill, Third Reading, $10^{\text {th }}$ Senate, 2017.

[23] IAB Europe (2014). Programmatic Trading. An IAB Europe whitepaper. IAB Europe.

[24] Kosorin, D. (2016) Introduction to Programmatic Advertising. Kosorin: Czechoslovakia.

[25] Kotler, P. (2000). Marketing Management: The millennium edition. Prentice-Hall.

[26] Lambrecht, A., \& Tucker, C. (2013). When Does Retargeting Work? Information Specificity in Online Advertising. Journal of Marketing Research, 50(5), 561-576. https://doi.org/10.1177/002224371305000508

[27] Lee, S. (2017). Distributed Machine Learning for Network Big Data. Big Data and Computational Intelligence in Networking, 331-350. https://doi.org/10.1201/9781315155678-17

[28] Lee, S. (2020). A Study on Consent of the GDPR in Advertising Technology focusing on Programmatic Buying. SSRN Electronic Journal. https://doi.org/10.2139/ssrn.3616651

[29] Martínez Martínez, I., \& Aguado, JM (2014). Mobile advertising: present and future impact on the digital content ecosystem. Journal of the Spanish Association for Communication Research, 1 (1), 76-85. https://doi.org/10.24137/raeic.1.1.8

[30] Martínez-Martínez, I. J., Aguado, J.-M., \& Boeykens, Y. (2017). Ethical Implications of Digital Advertising Automation: the Case of Programmatic Advertising in Spain. El Profesional De La Información, 26(2), 201. https://doi.org/10.3145/epi.2017.mar.06

[31] Miller, M. (2011). The Ultimate Web Marketing Guide. Pearson Education.

[32] NCC. (2019). NCC Hinges Nigeria's 122 million Internet users protection on effective governance. Nigerian Communications Commission. https://www.ncc.gov.ng/stakeholder/mediapublic/news-headlines/614-ncc-hinges-nigeria-s-122-millioninternet-users-protection-on-effective-governance.

[33] Nunan, D., \& Di Domenico, M. L. (2013). Market Research and the Ethics of Big Data. International Journal of Market Research, 55(4), 505-520. https://doi.org/10.2501/ijmr-2013-015

[34] Pal, K., \& Pal, T. (2019). Effect of Advertisement on Consumer Behavior. International Journal of Management Technology and Engineering.

https://www.academia.edu/38632794/Effect_of_Advertisement_o n_Consumer_Behavior.

[35] Pew Research Center. (2019). Privacy and information sharing: Scenarios. Pew Research Center: Internet, Science \& Tech. https://www.pewresearch.org/internet/interactives/privacyscenarios/.

[36] Ponemon Institute. (2016). Data Risk in the Third-Party Ecosystem: Third Annual Study. Ponemon Institute. https://www.ponemon.org/userfiles/filemanager/nvqfztft3qtufvi5gl $60 /$

[37] Schafer, A. \& Weiss, O. (2016) Understanding Demand-SidePlatforms. In Bush, O (Eds), Programmatic Advertising The Successful Transformation to Automated, Data-Driven Marketing in Real-Time, Switzerland, Springer International Publishing

[38] Shehu, E., Abou Nabout, N., \& Clement, M. (2020). The risk of Programmatic Advertising: Effects of Website Quality on Advertising Effectiveness. SSRN Electronic Journal. https://doi.org/10.2139/ssrn.3524447 
[39] Solomon, M. R., Askegaard, S., Hogg, M. K., \& Bamossy, G. J. (2006). Consumer Behaviour: A European Perspective. Pearson.

[40] Statista Research Department. (2021). Nigeria Mobile Internet Users 2025. https://www.statista.com/statistics/972896/nigeria-mobile-internetusers/.

[41] Statista Research Department. (2021). Nigeria Online Ad Revenue 2023. Statista. https://www.statista.com/statistics/508900/nigeriainternet-ad-revenue/.

[42] Supplementary Act A1SA.1F01F10 On Personal Data Protection Within ECOWAS, 2010, Article https://www.statewatch.org/media/documents/news/2013/mar/eco was-dp-act.pdf

[43] The National Information Technology Development Agency. (2019). Nigeria Data Protection Regulation 2019 - NDPR. NIGERIA DATA PROTECTION REGULATION https://ndpr.nitda.gov.ng/Content/Doc/NigeriaDataProtectionRegu lation.pdf.

[44] Tucker, C. E. (2012, January 2). The Economics of Advertising and Privacy. International Journal of Industrial Organization. https://www.sciencedirect.com/science/article/pii/S016771871100 1147.
[45] Wang, J., Zhang, W., \& Yuan, S. (2017). Display advertising with real-time Bidding (RTB) and Behavioural targeting. ArXiv. https://doi.org/10.1561/9781680833119

[46] Watts, M. (2016). Programmatic Advertising: Shaping Consumer Behavior or Invading Consumer Privacy? Undergraduate distinction thesis. KB Home. http://kb.osu.edu/dspace/handle/1811/76764.

[47] What is Programmatic Advertising? The Ultimate Guide (2019). Match2One. (2021, August https://www.match2one.com/blog/what-is-programmaticadvertising/.

[48] White, G. R. T., \& Samuel, A. (2019). Programmatic Advertising: Forewarning and Avoiding Hype-Cycle Failure. Technological Forecasting and Social Change. https://www.sciencedirect.com/science/article/pii/S004016251831 4902.

[49] World Bank. (2020). Mobile Cellular Subscriptions - Nigeria. World Bank Data. https://data. worldbank.org/indicator/IT.CEL.SETS?end=2019\&loc ations $=$ NG\&start $=1960 \&$ view $=$ chart.

[50] Zuboff, S. (2019). The Age of Surveillance Capitalism: The Fight for the Future at the New Frontier of Power. Profile Books. 